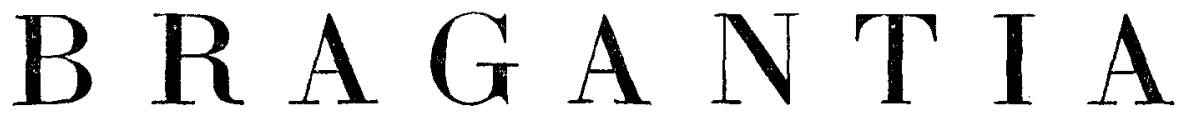

Boletim Científico do Instituto Agronômico do Estado de S. Paulo

Vol. 31

Campinas, janeiro de 1972

N. ${ }^{\circ} 5$

\title{
DETERMINAÇÃO DE CÁLCIO E DE MAGNÉSIO EM PLANTAS, POR FOTOMETRIA DE CHAMA DE ABSORÇÃO ( $\left.{ }^{1}\right)$
}

Ondino Cleante Bataglia $\left({ }^{2}\right)$ e J. Romano Gallo $\left({ }^{2}\right)$, engenheiros-agrônomos, Seção de Química Analítica, Instituto Agronômico

\section{SINOPSE}

As concentrações de cálcio e magnésio em extratos de plantas podem ser determinadas por fotometria de chama de absorção com a precisão e exatidão requeridas, mediante a adição de lantânio na concentração de $0,1 \%$, como agente protetor.

Para obtenção dos dados utilizou-se um espectrofotômetro Perkin-Elmer, modelo 303, equipado com sistema digital de leitura.

\section{1 - INTRODUÇÃO}

O cálcio e o magnésio são elementos essenciais ao desenvolvimento das plantas. Para estudo de seus efeitos na nutrição vegetal, técnicas apropriadas têm sido utilizadas para avaliação da ocorrência desses elementos nos tecidos.

Dentre as técnicas mais empregadas, citam-se a colorimetria $(\mathbf{1}, \mathbf{9})$, a complexometria $(\mathbf{7})$ e a fotometria de chama $(2,3,4,5,8)$. A fotometria de chama de absorção apresenta suficiente sensibilidade na determinação de cálcio e de magnésio, além da possibilidade de automatização que ofcrece nas análises de plantas.

(1) Trabalho subvencionado pelo Acordo Instituto Agronônico - Banco Nacional de Desenvolvimento Econômico, Projeto 19 - Contrato FUNDEPRO 42. Recebido para publicação $\mathrm{em}$ 19 de agosto de 1971.

$c^{2}$ ) Com bolsa de suplementação do CNPq. 
No presente trabalho foram estudados os aspectos relativos às interferências de diversos íons, e o método desenvolvido foi aplicado nas análises de material vegetal.

\section{2 - MATERIAL E METODOS}

As análises foram procedidas num espectrofotòmetro Perkin Elmer, modelo 303, equipado com dispositivo de leitura digital DCR-1. Usou-se chama de ar-acetileno, com queimador provido de fenda de $0,1 \mathrm{~cm}$ de largura por $10 \mathrm{~cm}$ de comprimento. Na relação seguinte são apresentadas as condições de trabalho e os ajustes do aparelho.

\section{Cálcio Magnésio}

Comprimento de onda, $\stackrel{\circ}{\AA}$

4227

2852

Fenda, mm

Corrente da làmpada, $\mathrm{mA}$

15

Vazão de acetileno

Vazão de ar

7,5

8

Dentre os reagentes empregados são mencionados os seguintes:

Solução-padtão de cálcio - Pesaram-se $2,500 \mathrm{~g}$ de $\mathrm{CaCO}_{3}$, p.a. seco, que foram dissolvidos com solução de HCI $6 \mathrm{~N}$. O material foi transferido para balão volumétrico de $1000 \mathrm{ml}$, e o vome completado com água destilada. A solução assim preparada continha $1,0 \mathrm{mg}$ de cálcio por mililitro.

Soluçāo-padrão de magnésio - Dissolveu-se $0,500 \mathrm{~g}$ de magnésio metálico em $15 \mathrm{ml}$ de solução de $\mathrm{HCl} 6 \mathrm{~N}$. O material foi transferido para balão volumétrico de $500 \mathrm{ml}$, e o volume completado com água destilada. A solução assim preparada continha 1,0 mg de magnésio por mililitro.

Solução-estoque de lantànio - Umedeceram-se 5,86 g de $\mathrm{La}_{2} \mathrm{O}_{3}$ com água destilada. Juntaram-se aos poucos $25 \mathrm{ml}$ de $\mathrm{HCl}$ e di- 
luiu-se a 1 litro com água destilada. Essa solução continha $0,5 \%$ de lantânio.

\section{Cloreto de estròncio.}

\section{Ácidos e outros reagentes p.a.}

$\mathrm{Na}$ primeira fase do trabalho foram estudados os aspectos analíticos visando à eliminação dos íons interferentes. Fixour-se um nível médio para o cálcio e para o magnésio, dentro da faixa ótima de sensibilidade para ambos, e fez-se a adição de quantidades crescentes de cada interferente, acima das que normalmente ocorrem nas plantas.

A eliminação das interferências foi tentada com a adição dos agentes protetores, estrôncio ou lantànio, nas concentraçōes de $500 \mathrm{ppm}$ de $\mathrm{Sr}$ e 0,1\% de La na concentração final.

$\mathrm{Na}$ aplicação do método para análise de material vegetal, pesaram-se $0,200 \mathrm{~g}$ da amostra preparada segundo Lott e outros ( $\boldsymbol{( 9 )}$ e procedeu-se à digestão em meio de ácido nítrico e perclórico, diluindo-se a solução a $50 \mathrm{ml}$ com água destilada. Uma alíquota (2 a $10 \mathrm{ml}$ ) do extrato foi transferida para balão volumétrico de $50 \mathrm{ml}$. Juntaram-se $10 \mathrm{ml}$ da solução-estoque de lantânio e completou-se o volume, de forma a garantir uma concentração de $0,1 \%$ em lantânio. As concentrações de cálcio e magnésio nas amostras foram determinadas por referència a uma curva-padrão obtida com soluções que continham 0 a $10 \mathrm{ppm}$ de cálcio, 0 a $2 \mathrm{ppm}$ de magnésio e $0,1 \%$ de lantânio.

\section{3 - RESULTADOS E DISCUSSÃO}

\section{1 - INTERFERENCIA DE IONS}

As interferências nas determinações de cálcio e magnésio por fotometria de chama de absorção, são principalmente de natureza química $(6,11)$. Assim, certos íons formam com o cálcio e o magnésio compostos refratários, que não se dissociam $\mathrm{cm}$ temperaturas relativamente baixas, como a da chama de ar-acetileno. 
A presença de $20 \mathrm{ppm}$ de $\mathrm{Na}^{+}, 50 \mathrm{ppm}$ de $\mathrm{K}^{+}, 1 \mathrm{ppm}$ de $\mathrm{Zn}^{2}+$ ou de $\mathrm{Cu}^{2}+$ não apresentou nenhum efeito sobre a absorbância de uma solução que continha $5 \mathrm{ppm}$ de cálcio e/ou $1 \mathrm{ppm}$ de magnésio.

Na concentração de $100 \mathrm{ppm}$, o íon $\mathrm{Ca}^{2+}$ não afetou a absorbância de uma solução que continha $1 \mathrm{ppm}$ de magnésio. Da mesma forma, $100 \mathrm{ppm}$ de $\mathrm{Mg}^{2}+$ não interferiram na absorbância de uma solução que continha $5 \mathrm{ppm}$ de cálcio.

A presença de $100 \mathrm{ppm}$ de cada um dos aníons $\mathrm{PO}_{4}^{3-}, \mathrm{SO}_{4}^{2-}$, $\mathrm{NO}_{3}^{-}$, de $0,1 \%$ de $\mathrm{ClO}_{\overline{4}}^{-}$ou de $2 \%$ de $\mathrm{Cl}^{-}$não interferiu na absorbância de soluções com 1 ppm de magnésio. Entretanto, na determinação do cálcio, observou-se um decréscimo na absorbância das soluções quando em presença dos aníons $\mathrm{PO}_{4}^{3-}$ e $\mathrm{SO}_{4}^{2-}$.

No quadro 1 são apresentados os resultados dos efeitos da adição dos íons $\mathrm{Al}^{3+}, \mathrm{Fe}^{3+}, \mathrm{Mn}^{2+}, \mathrm{Si}^{4+}, \mathrm{PO}_{4}^{3-}$ e $\mathrm{SO}_{4}^{2-}$ sobre a absorbância de soluções que encerravam $5 \mathrm{ppm}$ de cálcio e 1 ppm de magnésio. Observou-se que a determinação de magnésio só foi afetada na presença de $\mathrm{Al}^{3+}$ ou $\mathrm{Si}^{4+}$, e a do cálcio, por todos os íons citados.

A eliminação do decréscimo de absorbância provocado por íons interferentes sobre a determinação de cálcio e de magnésio tem sido feita mediante o uso de agentes protetores, lantânio e estrôncio $(\mathbf{2}, \mathbf{1 0})$. De acordo com esses trabalhos, o lantânio é usado na concentração de $1 \%$, e o estrôncio, 500 ppm.

Foram estudados os efeitos da variação da concentração de lantânio na eliminação das interferências dos íons $\mathrm{Al}^{3+}$ e $\mathrm{PO}{ }_{4}^{3-}$, na determinação de cálcio, e do íon $\mathrm{Al}^{3+}$, na determinação de magnésio. Para isso empregaram-se concentrações desde 0,05\% até $1,0 \%$ de lantânio, conforme se apresenta no quadro 2 . 
QuAdro 1. - Efeito de alguns íons sobre a absorbância de soluções que continham $1 \mathrm{ppm}$ de magnésio ou $5 \mathrm{ppm}$ de cálcio

\begin{tabular}{|c|c|c|c|}
\hline $\begin{array}{l}\text { fon } \\
\text { presente }\end{array}$ & $\begin{array}{c}\text { Concentração } \\
\text { do fon }\end{array}$ & Magnésio & Cálcio \\
\hline $\mathrm{Al}^{3+}$ & $\begin{array}{r}p p m \\
\\
0 \\
0,2 \\
0,5 \\
1,0 \\
10,0\end{array}$ & $\begin{array}{l}0,210 \\
0,208 \\
0,209 \\
0,205 \\
0,098\end{array}$ & $\begin{array}{c}0,142 \\
0,140 \\
0,138 \\
0,132 \\
0,013\end{array}$ \\
\hline $\mathrm{Fe}{ }^{3+}$ & $\begin{array}{r}0 \\
0,2 \\
0,5 \\
1,0 \\
10,0\end{array}$ & $\begin{array}{c}0,214 \\
0,214 \\
0,213 \\
0,215 \\
0,214\end{array}$ & $\begin{array}{l}0,141 \\
0,145 \\
0,141 \\
0,142 \\
0,133\end{array}$ \\
\hline $\mathrm{Mn}^{2+}$ & $\begin{array}{r}0 \\
0,2 \\
0,5 \\
1,0 \\
10,0\end{array}$ & $\begin{array}{l}0,214 \\
0,214 \\
0,213 \\
0,215 \\
0,214\end{array}$ & $\begin{array}{l}0,143 \\
0,145 \\
0,124 \\
0,113 \\
0,113\end{array}$ \\
\hline $\mathrm{Si}^{4+}$ & $\begin{array}{r}0 \\
2 \\
4 \\
10 \\
50\end{array}$ & $\begin{array}{l}0,240 \\
0,240 \\
0,238 \\
0,197 \\
0,078\end{array}$ & $\begin{array}{l}0,142 \\
0,108 \\
0,089 \\
0,053 \\
0,019\end{array}$ \\
\hline $\mathrm{PO}_{4}^{3-}$ & $\begin{array}{r}0 \\
2 \\
5 \\
10 \\
100\end{array}$ & $\begin{array}{l}0,223 \\
0,223 \\
0,222 \\
0,223 \\
0,227\end{array}$ & $\begin{array}{l}0,151 \\
0,151 \\
0,134 \\
0,124 \\
0,117\end{array}$ \\
\hline $\mathrm{SO}_{4}^{2-}$ & $\begin{array}{r}0 \\
2 \\
5 \\
10 \\
100\end{array}$ & $\begin{array}{l}0,238 \\
0,238 \\
0,238 \\
0,239 \\
0,241\end{array}$ & $\begin{array}{l}0,159 \\
0,156 \\
0,138 \\
0,142 \\
0,120\end{array}$ \\
\hline
\end{tabular}




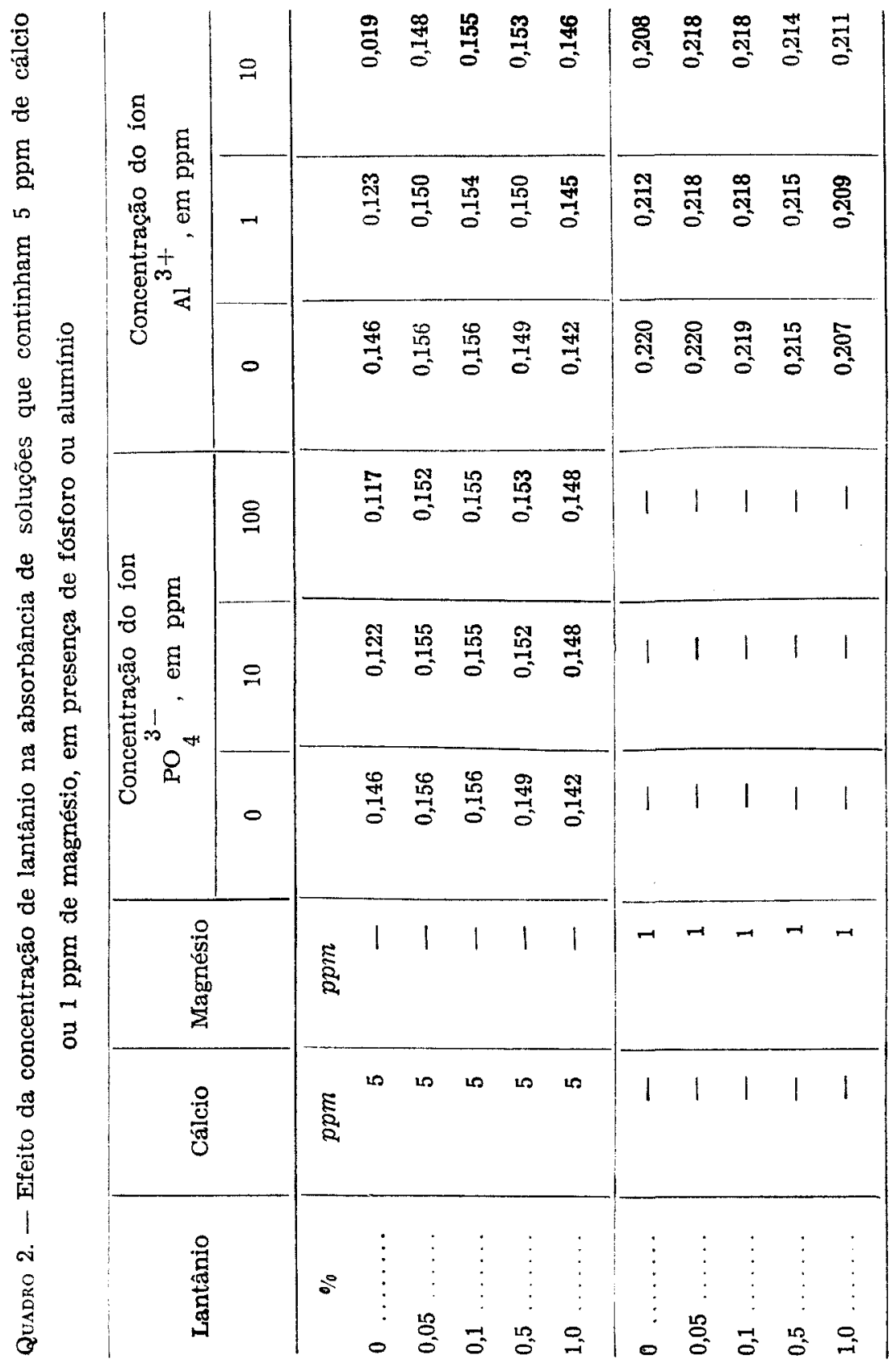


Esses dados mostram a viabilidade do emprego de uma concentração de $0,1 \%$ de lantânio para suprimir a interferência provocada pela presença de $10 \mathrm{ppm}$ de $\mathrm{Al}^{3+}$ sobre a determinação de cálcio e de magnésio, e pela presença de $100 \mathrm{ppm}$ de $\mathrm{PO}_{4}^{3-}$, na determinação de cálcio.

No quadro 3 pode ser observada a eficiência do uso de lantânio na concentração de $0,1 \%$ sobre a ação de outros íons que interferem na determinação de cálcio e de magnésio.

Quadro 3. - Absorbância de soluções com 1 ppm de magnésio ou 5 ppm de cáicio em presença de íons interferentes e 0,1\% de lantânio

\begin{tabular}{|c|c|c|c|}
\hline $\begin{array}{l}\text { fon } \\
\text { presente }\end{array}$ & $\begin{array}{l}\text { Concentração } \\
\text { do ín }\end{array}$ & Magnésio & Cálcio \\
\hline $\mathrm{Fe}^{3+}$ & $\begin{array}{r}p p m \\
\\
0 \\
0,2 \\
0,5 \\
1,0 \\
10,0\end{array}$ & $\begin{array}{l}\bar{I} \\
\overline{-}\end{array}$ & $\begin{array}{l}0,148 \\
0,147 \\
0,147 \\
0,150 \\
0,146\end{array}$ \\
\hline $\mathrm{Mn}^{2+}$ & $\begin{array}{r}0 \\
0,2 \\
0,5 \\
1,0 \\
10,0\end{array}$ & $\begin{array}{l}- \\
-\end{array}$ & $\begin{array}{l}0,144 \\
0,145 \\
0,146 \\
0,146 \\
0,145\end{array}$ \\
\hline$S i^{4+}$ & $\begin{array}{r}0 \\
0,2 \\
0,4 \\
10,0 \\
50,0\end{array}$ & $\begin{array}{l}0,239 \\
0,239 \\
0,238 \\
0,238 \\
0,237\end{array}$ & $\begin{array}{l}\mathbf{0 , 1 4 8} \\
0,146 \\
0,146 \\
0,147 \\
\mathbf{0 , 1 4 5}\end{array}$ \\
\hline $\mathrm{sO}_{4}^{2-}$ & $\begin{array}{r}0 \\
0,2 \\
0,5 \\
10,0 \\
100,0\end{array}$ & $\begin{array}{l}- \\
-\end{array}$ & $\begin{array}{l}0,156 \\
0,155 \\
0,154 \\
0,156 \\
0,159\end{array}$ \\
\hline
\end{tabular}


A influência do estrôncio (quadro 4) foi verificada para 500 ppm desse elemento em soluções que encerravam $5 \mathrm{ppm}$ de cálcio ou $1 \mathrm{ppm}$ de magnésio e concentrações crescentes dos íons $\mathrm{Al}^{3+}$ ou $\mathrm{Si}^{4+}$.

QUADRo 4. - Absorbâncias de soluções que continham 1 ppm de magnésio ou $5 \mathrm{ppm}$ de cálcio, sem e com $500 \mathrm{ppm}$ de estrôncio, na presença de alumínio ou silício

\begin{tabular}{|c|c|c|c|c|c|}
\hline \multirow[b]{2}{*}{ Alumínio } & \multirow[b]{2}{*}{ Silício } & \multicolumn{2}{|c|}{ Magnésio } & \multicolumn{2}{|c|}{ Cálcio } \\
\hline & & $\begin{array}{c}\text { Sem } \\
\text { estrôncio }\end{array}$ & $\begin{array}{c}\text { Com } \\
\text { estrôncio }\end{array}$ & $\begin{array}{c}\text { Sem } \\
\text { estrôncio }\end{array}$ & $\begin{array}{l}\text { Com } \\
\text { estrôncio }\end{array}$ \\
\hline$p p m$ & $p p m$ & & & & \\
\hline $\begin{array}{r}0 \ldots \ldots \\
0,5 \ldots \ldots \\
1,0 \ldots \ldots \\
5,0 \ldots \ldots \\
10,0 \ldots \ldots\end{array}$ & $\begin{array}{l}= \\
=\end{array}$ & $\begin{array}{l}0,210 \\
0,209 \\
0,205 \\
0,202 \\
0,198\end{array}$ & $\begin{array}{l}0,208 \\
0,208 \\
0,209 \\
0,207 \\
0,210\end{array}$ & $\begin{array}{l}0,142 \\
0,138 \\
0,132 \\
0,037 \\
0,013\end{array}$ & $\begin{array}{l}0,162 \\
0,154 \\
0.155 \\
0.149 \\
0,142\end{array}$ \\
\hline$\frac{-}{-}$ & $\begin{array}{r}0 \ldots \\
10,0 \ldots \\
20,0 \ldots \\
50,0 \ldots \\
50\end{array}$ & $\begin{array}{l}0,240 \\
0,197 \\
0,151 \\
0,078\end{array}$ & $\begin{array}{l}0,240 \\
0,237 \\
0,220 \\
0,160\end{array}$ & $\begin{array}{l}0,141 \\
0,078 \\
0,057 \\
0,019\end{array}$ & $\begin{array}{l}0,148 \\
0,099 \\
0,057 \\
0,019\end{array}$ \\
\hline
\end{tabular}

Pelos resultados, verificou-se que $500 \mathrm{ppm}$ de estrôncio não suprimiram a interferência do alumínio e do silício na determinação de cálcio. Na determinação de magnésio, o estrôncio eliminou a interferência do alumínio, mas não a do silício.

\section{2 - APLICAÇÃO DO MÉTODO}

\subsection{1 - ANÁLISE DE SOLUÇÕES SINTÉTICAS}

Foram preparadas soluções sintéticas com íons interferentes, correspondendo às seguintes concentrações dos elementos na matéria seca das plantas: $\mathrm{Al}^{3+}, \mathrm{Fe}^{3}+$ e $\mathrm{Mn}^{2}+500 \mathrm{ppm} ; \mathrm{Si}^{4+}$ $1 \%, \mathrm{PO}_{4}^{3-}$ e $\mathrm{SO}_{4}^{2-} 0,5 \%$. 
Quadro 5. - Recuperação de magnésio e cálcio em soluções sintéticas que continham outros íons, em ausência e em presença de lantânio na concentração de $0,1 \%$

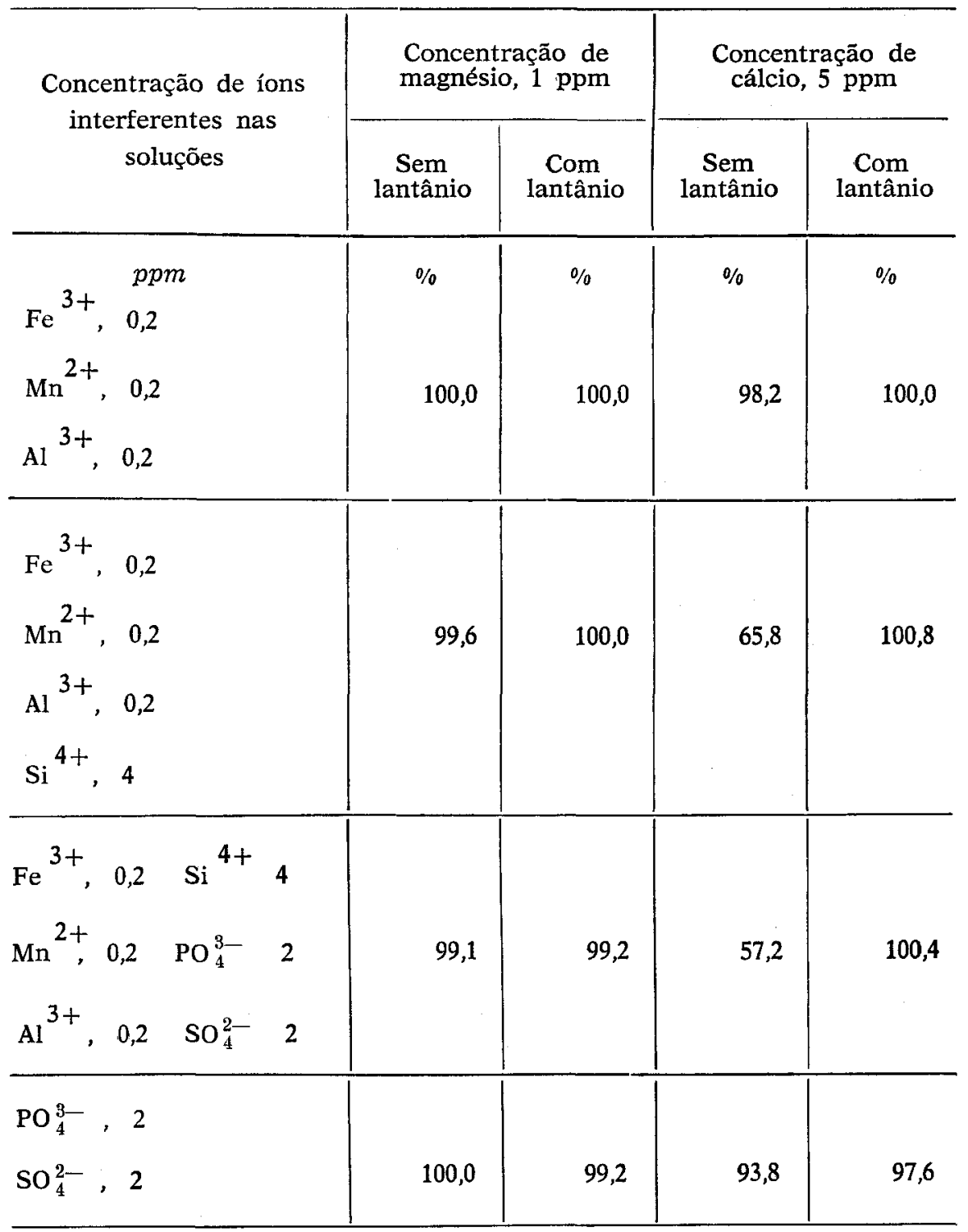


Como se observa pelos resultados do quadro 5 , a recuperação de magnésio nessas soluções foi total tanto na ausência como na presença de lantânio, podendo em tais casos ser dispensada a adição de lantânio. A recuperação de cálcio na ausência de lantânio foi prejudicada, constatando-se efeito depressivo acentuado do silício. $\mathrm{Na}$ presença de lantânio a recuperação foi total.

O procedimento para a determinação de cálcio e de magnésio foi testado, a seguir, com soluções que continham 0,5 e $10 \mathrm{ppm}$ de cálcio ou 0,1 e $2 \mathrm{ppm}$ de magnésio em presença de diversos íons. Dessa maneira, várias soluções foram preparadas para formarem amostras que continham as concentrações de íons apresentadas no quadro 6 . As concentrações dos íons interferentes estão bem acima das normalmente presentes em extratos de amostras de plantas.

Os dados do quadro 6 mostram que a recuperação de cálcio e magnésio foi satisfatória em todos os casos mencionados.

\subsection{2 - ANALISE DE PLANTAS}

Para a determinação de cálcio e magnésio em plantas, procedeu-se à digestão de $0,200 \mathrm{~g}$ da amostra seca e moída, com $1 \mathrm{ml}$ de $\mathrm{HNO}_{3}$ e $0,5 \mathrm{ml}$ de $\mathrm{HClO}_{4}$, conduzindo-se o volume a $50 \mathrm{ml}$ (9) . Uma alíquota de 2 a $10 \mathrm{ml}$ foi transferida para balão de $50 \mathrm{ml}$, juntaram-se $10 \mathrm{ml}$ da solução-estoque de lantânio a $0,5 \%$ e completou-se o volume com água destilada.

$\mathrm{O}$ quadro 7 reúne os dados relativos à precisão da determinação de cálcio e de magnésio em plantas que encerravam concentrações variáveis desde $0,08 \%$ a $4,81 \%$ de cálcio e de $0,14 \%$ a $0,82 \%$ de magnésio na matéria seca da amostra. $\mathrm{O}$ método permite boa precisão, mesmo para amostras com concentrações relativamente baixas em cálcio e magnésio, como as que ocorrem em fruto de tomateiro.

Os dados do quadro 8 fornecem indicação sobre a exatidão do procedimento estudado para a determinação de cálcio e magnésio em vegetais. Alíquotas do mesmo extrato de diversos materiais vegetais foram analisadas sem e com a adição de cálcio ou de magnésio. A recuperação foi de $96 \%$ a $104 \%$ para o cálcio e de $95 \%$ a $103 \%$ para o magnésio. 
BATAGLIA \& GALLO

Jan., 1972 FOTOMETRIA DE CHAMA DE ABSORÇÃO. II.

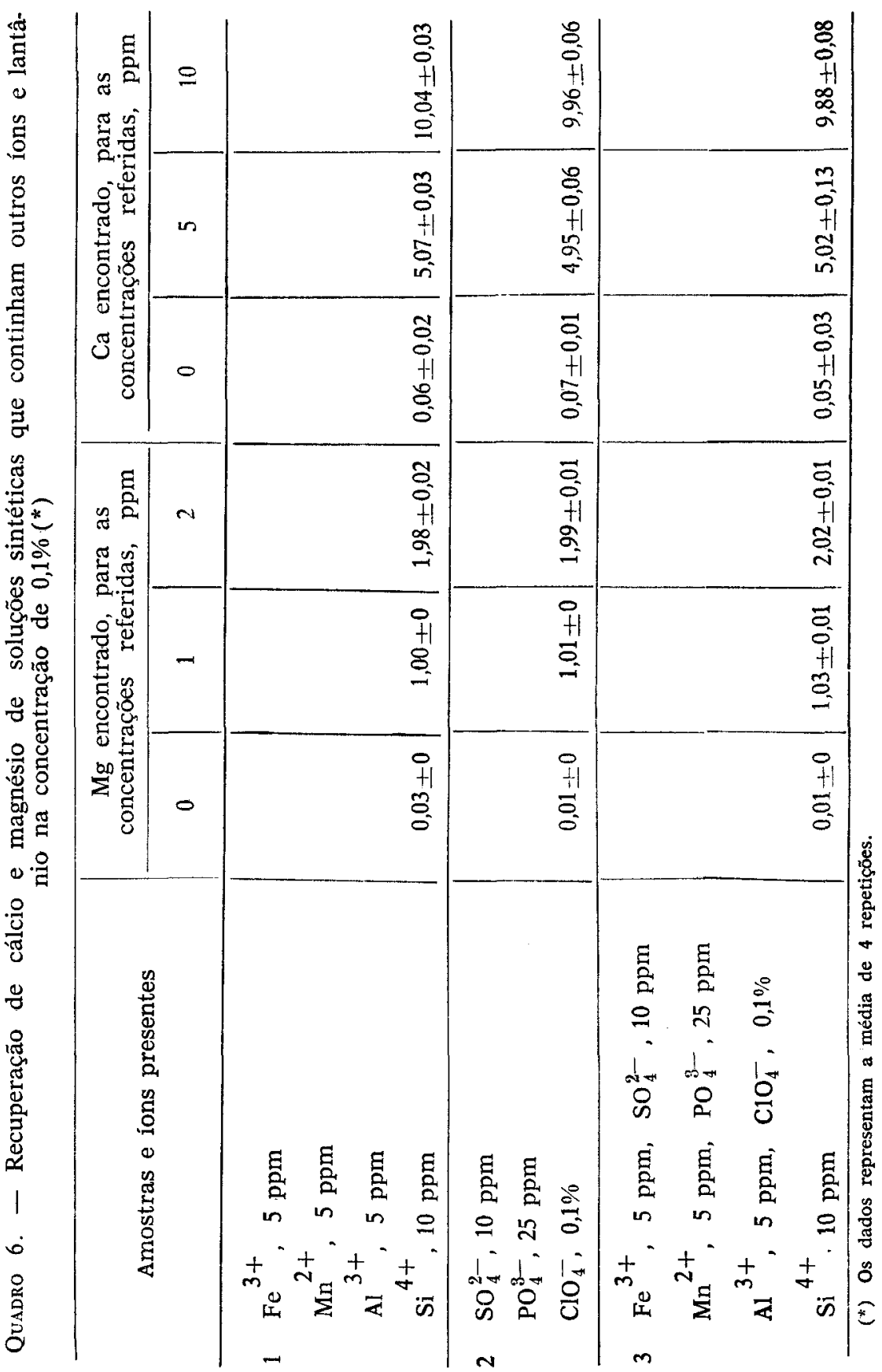


Vol. 31, N.o 5

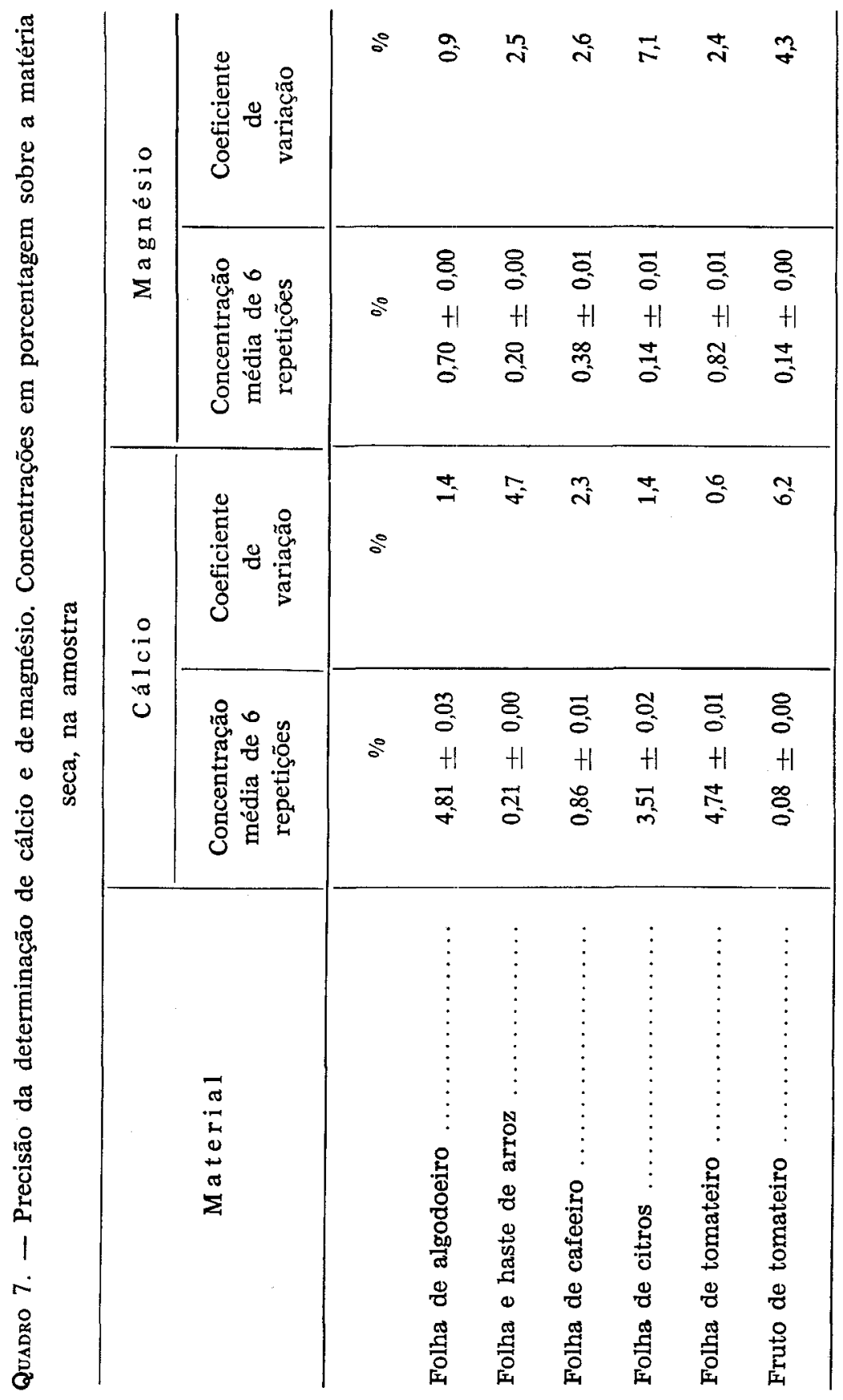




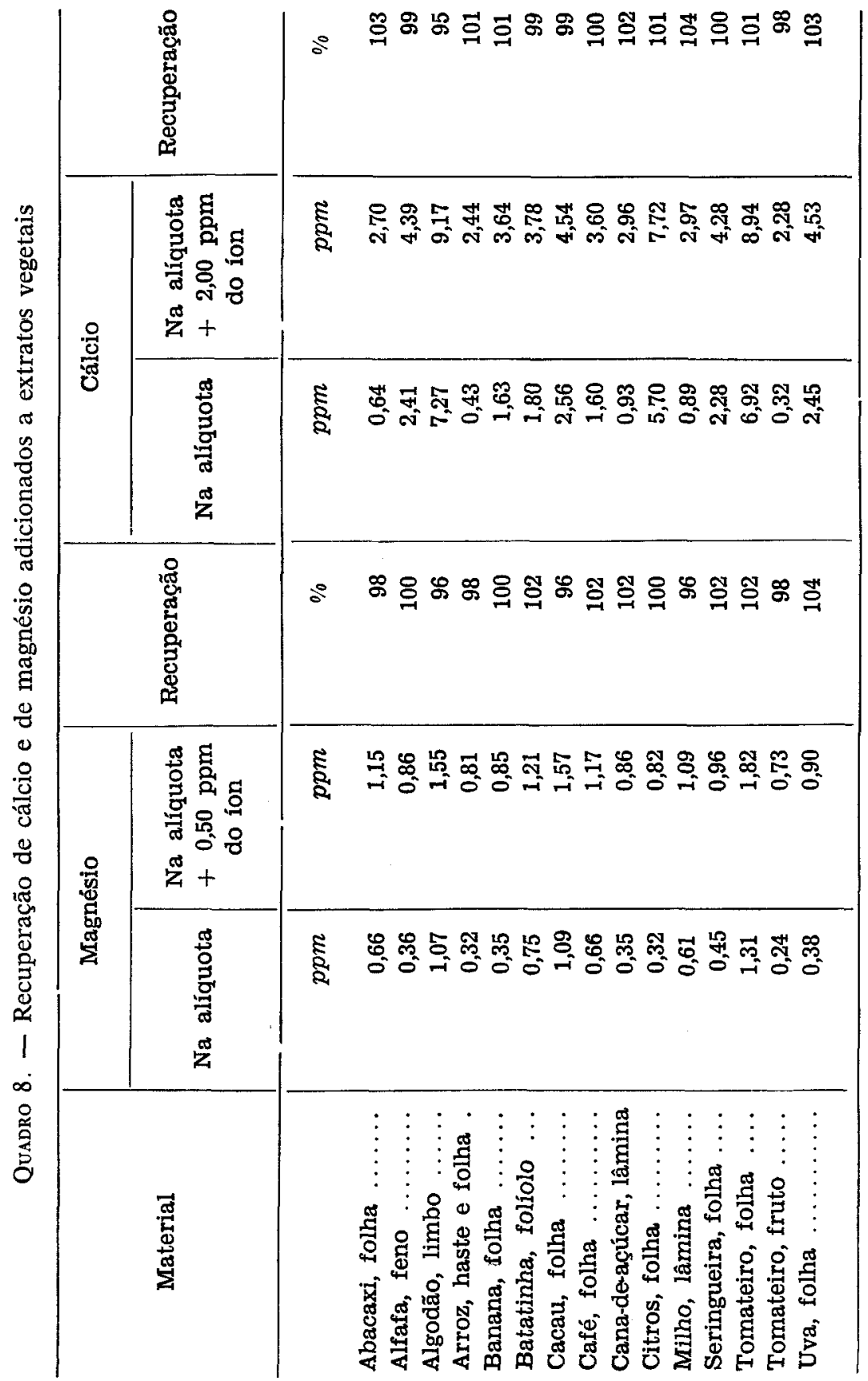




\section{4 - CONCLUSÕES}

Dentro dos limites de concentração dos íons estudados, verificou-se que a determinação de cálcio foi afetada pela presença de $\mathrm{Fe}^{3+}, \mathrm{Al}^{3+}, \mathrm{Mn}^{2+}, \mathrm{Si}^{4+}, \mathrm{PO}_{3-}^{3--}$ e $\mathrm{SO}_{4}^{2-}$; não interferiram os íons $\mathrm{Mg}^{2+}, \mathrm{K}^{+}, \mathrm{Na}^{+}, \mathrm{Cu}^{2+}, \mathrm{Zn}^{2+}, \mathrm{Cl}^{-}, \mathrm{NO}_{3}^{-}$e $\mathrm{ClO}_{4}^{-}$. Na determinação de magnésio houve interferência apenas dos íons $\mathrm{Al}^{3+} \mathrm{e} \mathrm{Si}^{4+}$.

A presença de $500 \mathrm{ppm}$ de estrôncio foi insuficiente para

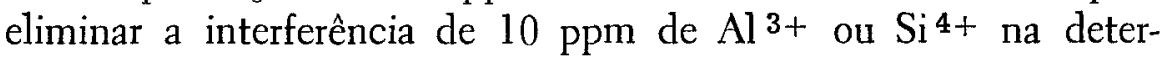
minação de $5 \mathrm{ppm}$ de cálcio. Na determinação de $1 \mathrm{ppm}$ de magnésio, o estrôncio evitou a interferência do ín $\mathrm{Al}^{3+}$, porém não a do $\mathrm{Si}{ }^{4+}$.

O uso de lantânio na concentração de $0,1 \%$ possibilitou a eliminação dos interferentes na determinação de cálcio e magnésio. A absorbância de uma solução com $5 \mathrm{ppm}$ de cálcio não foi

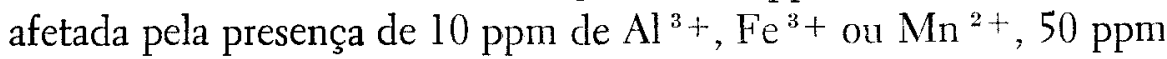
de $\mathrm{Si} 4+$ e 100 ppm de $\mathrm{PO}_{4}^{9-} \quad$ ou $\mathrm{SO}_{4}^{2-}$. A absorbância de uma solução com $1 \mathrm{ppm}$ de magnésio não foi afetada pela presença de $10 \mathrm{ppm}$ de $\mathrm{Al}^{3+}$ ou $50 \mathrm{ppm}$ de $\mathrm{Si}^{4+}$.

$\mathrm{O}$ método descrito forneceu bons resultados quanto à precisão e exatidão na determinação de cálcio e de magnésio em plantas.

DETERMINATION OF CALCIUM AND MAGNESIUM IN PLANT MATERIAL, BY ABSORPTION FLAME PHOTOMETRY

\section{SUMMARY}

A method for determination of calcium and magnesium by absorption flame photometry was studied using a Perkin-Elmer model 303 spectrophotometer equiped with digital concentration readout model DCR1.

The study of interferents was carried out with concentration usually present in plant material or even in higher concentrations to get information about the possibility of applying this method to other materials.

Within the limits of concentration studied, it was observed that calcium determination was affected by the ions $\mathrm{Fe}^{3+}, \mathrm{Al}^{3+}, \mathrm{Mn}^{2+}, \mathrm{Si}^{4+}$, 
$\mathrm{PO}_{4}^{3-}$ and $\mathrm{SO}_{4}^{2-}$. The ions $\mathrm{Mg}^{2+}, \mathrm{K}^{+}, \mathrm{Na}{ }^{+}, \mathrm{Cu}^{2+}, \mathrm{Zn}^{2+}, \mathrm{Cl}^{-}$, $\mathrm{NO}_{3}^{-}$and $\mathrm{ClO}_{4}^{-}$had no interference. Magnesium determination was affected only by the presence of the ions $\mathrm{Al}^{3+}$ and $\mathrm{Si}^{4+}$.

The use of $0.1 \%$ lanthanum solution suppressed the interference of 10 ppm of $\mathrm{Al}^{3+}, \mathrm{Fe}^{3+}$ or $\mathrm{Mn}^{2+}, 50 \mathrm{ppm}$ of $\mathrm{Si}^{4+}$ and $100 \mathrm{ppm}$ of $\mathrm{PO}_{4}^{3-}$ or $\mathrm{SO}_{4}^{2-}$ on a $5 \mathrm{ppm}$ calcium solution. It suppressed also the effect of 10 ppm of $\mathrm{Al}^{3+}$ or $50 \mathrm{ppm}$ of $\mathrm{Si}^{4+}$ in the absorbance of 1 ppm magnesium solution.

In the application of the method for calcium and magnesium in plant analysis, $0.200 \mathrm{~g}$ of dried plant material was digested with $1 \mathrm{ml}$ of nitric acid and $0.5 \mathrm{ml}$ percloric acid. The volume was completed to $50 \mathrm{ml}$ with distijled water. A portion (2 to $10 \mathrm{ml}$ ) was transfered to a $50 \mathrm{ml}$ volumetric flask, lanthanum was added to a final concentration of $0.1 \%$ and the volume was taken to $50 \mathrm{ml}$. Calcium and magnesium in plant material were determined using calibration curves, obtained with calcium solutions varying from 0 to $10 \mathrm{ppm}$ and magnesium solutions varying from 0 to $2 \mathrm{ppm}$ (both had $0.1 \%$ lanthanum).

The method here described yields good accuracy and precision, and seems to be suitable for routine analysis of plant material.

\section{LITERATURA CITADA}

1. BERGAMIN FILHO, H. O método colorimétrico do tiazol amarelo na determinação do magnésio. Piracicaba, Esc. Sup. Agric. "Luiz de Queiroz", 1961. 56p. (Tese) (Mimeografado)

2. BERRY, W. L. \& JOHNSON, C. M. Determination of calcium and magnesium in plant material and culture solutions, using atomic absorption spectroscopy. Appl. Spectroscopy 20:209-211, 1966.

3. DAVID, D. J. Atomic absorption analysis of plant materials with particular reference to manganese and iron. Atomic Absorption Newsletter, 1962. 6p. (N.०9)

4. - Determination of calcium in plant material by atomic absorption spectrophotometry. Analyst 84:536-545, 1959.

5. — Determination of zinc and other elements in plants by atomic absorption spectroscopy. Analyst 83:655-661, 1958.

6. DICKSON, R. E. \& JOHNSON, C. M. Interferences associated with the determination of calcium by atomic absorption. Appl. Spectroscopy 20:214-218, 1966. 
7. GLORIA, N. A., CATANI, R. A. \& MATUO, T. Determinação de cálcio e magnésio em plantas, pelo método do EDTA. An. Esc. Agric. Queiroz 22:154-171, 1965.

8. LOTT, W. L.; MCCLUNG, A. C.; VITA, R. \& GALLO, J. R. Levantamento de cafezais em São Paulo e Paraná pela análise foliar. São Paulo, Instituto de Pesquisas IRI, 1961. 69p. (Boletim 26)

9. —; NERY, J. P.; GALLO, J. R. \& MEDCALF, J. C. A técnica de análise foliar aplicada ao cafeeiro. Campinas, Instituto Agronômico, 1956. 29p. (Boletim 79)

10. PERKIN-ELMER. Analytical methods for atomic absorption spectrophotometry. Norwalk, Connecticut, 1968.

11. SLAVIN, W. Atomic absorption spectroscopy. New York, Interscience, 1968 . $307 \mathrm{p}$. 